veracity of climate change. One tactic is 'astroturfing' - the development of faux grass-roots organizations that aim to transform lobbyists into activists and that can make source-funding and motives difficult to track. A strategy originally used by the tobacco industry, it has been honed and expanded by groups funded by the oil, gas and coal industries.

The authors also identify leading sceptics who are often presented as climate 'experts', and debunk their credentials, affiliation histories and funding pathways. The words of these spokespeople, who are talented but often acting outside their area of expertise, have a long reach through the 'echo chamber' of blogs, newspaper editorials, reports, public talks and other forms of message reinforcement. Hoggan and Littlemore offer citations to support their strong assertions. They also make the reader keenly aware of the perils of legal action against those who have challenged sceptics in the past; the chapter on strategic lawsuits against public participation is disturbing.

Hoggan and Littlemore's arguments will not be new to followers of climate-change debates, but their narrative deftly exposes a landscape of denial that is unrelenting, extensive, international and tactically rich. It is a convincing and riveting tale of conspiracy that gives context to the e-mails leaked last year from the Climatic Research Unit at the University of East Anglia in Norwich, UK, and the besieged sense one gets from the communications of scientists caught in the vortex of efforts to unseat their research.

Aimed at a mass readership, the book does not address the changes that are under way through the new media inherent in the 'echo chamber', nor does it unpack models for the public understanding of science, the role of expertise, or relationships between science, the media and politics. In the United States, the partisan differences that have been revealed in polls about climate change are directly attributed to patterns of media consumption. The authors do consider the difficulties for reporters in assessing the claims of sceptics, and the increasingly limited resources available for investigative and scientific reporting.

Climate Cover-Up tackles brilliantly the strategies deployed when messages that are "tested for effectiveness, but not accuracy" are used to spread doubt about climate change. The authors' solution is to offer a prescription for navigating expertise and to demand leadership with the courage to act. To use their metaphor, this is what is needed before we all end up like lemmings, plunging over the cliff together. Candis Callison is assistant professor in the School of Journalism at the University of British Columbia, Vancouver V6T 1Z2, Canada. e-mail: candis.callison@ubc.ca

\section{Georgia's fossils on view}

\section{Dmanisi Archaeological Site \\ Dmanisi, Georgia \\ See go.nature.com/hzXeZy}

Visitors are now welcome at the Dmanisi archaeological site in Georgia - famed as the location of the oldest hominin fossils to be found outside Africa. The first phase of an on-site museum, a modern wooden-and-steel shelter, opened in September 2009 to protect the central dig and allow the public to explore the site. Later this year, construction is due to start on a visitor centre that will display some important finds.

Dmanisi, a village about 85 kilometres southwest of Georgia's capital, Tbilisi, lies on the ancient Silk Road linking Europe and Asia. The site is rich in medieval and Bronze Age artefacts, but it is the wealth of palaeolithic finds that has put it on the scientific map. Fossils of human ancestors 1.8 million years old were unearthed here in 1991 to great fanfare. These small-brained hominins seem to be more primitive than the fossils of Homo erectus found in Asia, previously the earliest known human-like species outside Africa.

"It's the jackpot," explains David Lordkipanidze, director of the Georgian National Museum and project leader for the Dmanisi museum. "We must concentrate our efforts on how best to use this jackpot." With funding from the United Nations Educational, Scientific and Cultural Organization (UNESCO), the multinational oil firm BP and a Rolex Award for Enterprise in 2005, he hired the French architects Studio Milou to build the museum.

On arrival, the visitor is directed around the central dig along wooden walkways, past Bronze Age burials towards a viewing gallery from where they can watch the archaeologists at work in the excavations. A nearby room shows films about the original discoveries, including interviews with scientists and historical information about the site, which helps to put the finds into context.

Perched on a rocky promontory overlooking the main site are the remains of a medieval fortress, with an inner castle, holy shrines and a secret escape tunnel. One shrine from the thirteenth century has an unusual gate engraved with ornaments and manuscripts. The entire settlement is thought to have included cellars, houses, a mosque and a madrassa, or school, at a time when Dmanisi flourished as the crossroad of major travel routes.

Beyond the palaeolithic excavation, there are medieval passageways and a maze of ancient storage pits and cellars. In 1996, two Bronze Age tombs were investigated in a valley nearby, revealing vases, arrowheads and a bronze dagger blade dating to the second millennium $\mathrm{BC}$.

The Dmanisi museum is one of a suite of cultural institutions planned for Georgia. Learning from the German experience of modernization after reunification, Lordkipanidze is collaborating with the Berlin Museum. The plan is to refurbish a string of museums and galleries along Tbilisi's main Rustaveli Avenue. He envisages that it will become an area similar to the National Mall in Washington DC, or Berlin's Museum Island. "Georgia today is searching for its place in the world, and cultural heritage is one of the opportunities to put it on the map," he says. "Science is not just for scientists. Archaeology is one of the small tools we have to pave our way towards Europe."

With UNESCO support together with funding from the Smithsonian Institution in Washington DC and a big European Union twinning project between the Georgian National Museum and the Prussian Cultural Heritage Foundation, Lordkipanidze has every reason to be confident despite the daunting task ahead.

There is a desperate need for better infrastructure if Dmanisi is to support more tourists, but it is well worth the trek from Tbilisi.

Katharine Barnes is a journalist based in Baku,

Azerbaijan.

e-mail: kjbbarnes@gmail.com 